\title{
A Conceptual Analysis of Individuals with an Autism Spectrum Disorder Engaging in Mass Violence
}

\author{
Allely $\mathrm{CS}^{1^{*}}$, and Faccini $\mathrm{L}^{2}$ \\ ${ }^{1}$ School of Health Sciences, University of Salford, Manchester, England and also affiliate member of the Gillberg \\ Neuropsychiatry Centre, Sahlgrenska Academy, University of Gothenburg, Gothenburg, Sweden \\ ${ }^{2}$ Lino Faccini, Licensed Psychologist, United States
}

*Corresponding author: Allely CS, School of Health Sciences, University of Salford, Manchester, England and also affiliate member of the Gillberg Neuropsychiatry Centre, Sahlgrenska Academy, University of Gothenburg, Sweden, Email: c.s.allely@salford.ac.uk

Citation: Allely CS, Faccini L (2017) A Conceptual Analysis of Individuals with an Autism Spectrum Disorder Engaging in Mass Violence, J Forensic Crime Stu 1: 105

Article history: Received: 27 January 2017, Accepted: 22 June 2017, Published: 23 June 2017

\begin{abstract}
Research investigating the potential mechanisms underlying the development of a mass shooter is currently in its infancy. One of the main explanations for this is the challenges with applying conventional research techniques when trying to understand this relatively rare group of extremely violent individuals. The three factors of autism-based deficits, psychopathology and deficient psychosocial development was adapted to include the 'Path to Intended Violence', to understand the possible route to mass shooting in a very small subgroup of individuals with ASD (namely, Anders Breivik, Dean Allen Mellberg and Adam Lanza).
\end{abstract}

Keywords: Autism Spectrum Disorder; Mass Shooting; Pathway to Intended Violence; Terrorism

\section{Introduction}

Research investigating the potential mechanisms underlying the development of a mass shooter is currently in its infancy [1]. There are inherent challenges in identifying individuals who are at high risk of committing an extremely violent act such as mass shooting. One of the main challenges is the fact that the behavior which we are trying to predict is a rare event. Any predictive strategy (even if reasonably accurate) suffers from significant limitations when attempting to identify true positives for a low base rate behavior without at the same time identifying a significant number of false positives [2,3].

A number of typical features in the mass shooter have been identified. For instance, the mass shooter is usually male (95\%), they are typically Caucasian (nearly two thirds are White), and older than murderers in general. Mass shooters also tend to have common psychological and behavioral characteristics such as: depression, resentment, social isolation, the tendency to externalize rather than internalize blame, fascination with graphically violent entertainment, and a significant interest in weaponry [4]. Again, going back to the challenges with trying to understand and predict this extremely violent behavior, in the general population these psychological and behavioral characteristics are fairly prevalent [5].

\section{Autism spectrum disorders and offending behavior}

A recent review looking at autism and offending behavior conducted by $\operatorname{Im}$ [6], highlighted that while there are a number of case reports indicating an increased risk of violence in people with ASD, there is no conclusive support for this in the prevalence studies conducted to date [6]. In fact, a relatively modest amount of literature has found that rather than being the perpetrator of violence, individuals with ASD may actually be more likely to be the victim [7]. Crucially, there are no studies which provide any support to the notion that individuals with ASD are more violent compared to individuals without a diagnosis of ASD [6]. Numerous studies have found that persons with ASD are not at increased risk of offending [8,9] and, in fact, there are a number of studies which have suggested that persons with ASD may be less likely to engage in violent offending behavior compared to the general population [10]; in fact, most individuals with ASD are law-abiding [8,11,12].

Studies have shown that mental health conditions are rarely a direct cause of violent offending behavior $[13,14]$. This is consistent with the views of Corner and Gill [15] who maintain that "lone-actor motivation is embedded in an ideological cause, developed over time, alongside a myriad of other proximal and distal risk factors not just mental disorder" [16] (pp. 565). However, Fitzgerald 
[17] argued that there is a very small subgroup of individuals with ASD who exhibit violent offending behaviors. In his recently published paper, Fitzgerald [18] highlights that school shootings and mass killings are not uncommonly carried out by individuals with neurodevelopmental disorders with frequent evidence of warning indicators. Allely and colleagues [19] recently investigated Fitzgerald's [17] theory in more detail by investigating the 73 mass shooting cases identified by Mother Jones for potential ASD. Evidence of ASD was found in six cases (8\%) which is eight times higher when compared to the prevalence found in the general population worldwide. Crucially, ASD may influence, but does not cause, an individual to commit an extreme violent act such as a mass shooting episode. In an earlier systematic review, Allely and colleagues' [20] findings tentatively indicated that these extreme forms of violence may be a result of a highly complex interaction of biological, psychological and sociological factors and that, potentially, a significant proportion of mass or serial killers may have had neurodevelopmental disorders such as ASD and head injury. Faccini [21] in his theoretical paper applied two different models in order to attempt to understand the intended mass violence in the case of Adam Lanza who had received a diagnosis of Asperger's syndrome (an autism spectrum disorder). The three factors of autism-based deficits, psychopathology and deficient psychosocial development was adapted to include the 'Path to Intended Violence', to understand the possible route to mass shooting in a very small subgroup of individuals with ASD.

\section{A Conceptual Analysis: Three Cases of Mass Shooting}

There have been cases that have come to the attention of the news regarding persons with autism spectrum disorder (ASD) (or strongly suspected ASD as in the case of Anders Breivik) who have committed acts of mass violence. However, a systematic study of this rare occurrence is not possible since many perpetrators actually commit suicide. Case analyses of publically-available information for the shooting violence perpetrated by Dean Allen Mellberg, Adam Lanza, and Ander's Breivik were completed to identify any common patterns or pathways; the case of Elliott Rodger was also analyzed but there wasn't enough publically- available information or data gleaned from reports or his own manifesto consistent with an autism spectrum disorder. As a result, Rodger's case was not included in this conceptual analysis. (Table 1) Especially because the individuals were not personally evaluated by the authors, the conclusions that are offered may be regarded as an exploratory study. However, this paper does identify that although ASD-based deficits interacted with psychopathology in their clinical presentation, what was common, critical, and proximal for mass violence to occur was that these factors contributed or co-existed with grievances that put these individuals on the Path towards Intended Violence. Basically, anyone who starts with grievances and crystalizes these in ideation, makes the violence-only decision, and then progresses along the subsequent steps of researching and planning, preparation and then breaching security would most likely engage in significant violence. The most critical factor is proposed to be engaging in the Path towards Intended Violence.

\begin{tabular}{|c|c|c|c|c|c|}
\hline Name & Diagnosis & ASD-Based Deficits & $\begin{array}{c}\text { Co-morbid Mental Health } \\
\text { Conditions }\end{array}$ & Pathway \\
\hline Adam Lanza & Autism & $\begin{array}{c}\text { Sensory Sensitivities, Abnormal } \\
\text { fixated interests }\end{array}$ & $\begin{array}{c}\text { OCD, Depression, Suicidal/ } \\
\text { Homicidal Ideation }\end{array}$ & $\begin{array}{c}\text { Personal Grievance + } \\
4 \text { steps of PIV }\end{array}$ & $\begin{array}{c}\text { Elementary School } \\
\text { Shooting }\end{array}$ \\
\hline $\begin{array}{c}\text { Dean Allen } \\
\text { Mellberg }\end{array}$ & Autism & Unknown & $\begin{array}{c}\text { Paranoid Personality } \\
\text { Disorder, Anxiety }\end{array}$ & $\begin{array}{c}\text { Personal Grievance + } \\
4 \text { steps PIV }\end{array}$ & Air Base Shooting \\
\hline $\begin{array}{c}\text { Anders } \\
\text { Breivik }\end{array}$ & $\begin{array}{c}\text { Asperger's } \\
\text { Syndrome }\end{array}$ & $\begin{array}{c}\text { Lack of emotion, empathy, } \\
\text { imagination, obsessive with } \\
\text { numbers, writing, deficits } \\
\text { understanding social cues }\end{array}$ & $\begin{array}{c}\text { Narcissistic P.D., Depression } \\
\text { Narcissistic Decompensation }\end{array}$ & $\begin{array}{c}\text { Personal to Political } \\
\text { Grievances }+ \\
4 \text { Steps of PIV }\end{array}$ & $\begin{array}{c}\text { Oslo bombing } \\
\text { and Utøya Island } \\
\text { Shooting }\end{array}$ \\
\hline
\end{tabular}

Table 1: A summary of case analyses of three mass shootings by individuals with an ASD

The case analyzes of Lanza, Mellberg and Breivik have been previously presented [22-24]. In summary, Lanza and Mellberg were diagnosed with ASD while Breivik was strongly argued to have Asperger's Syndrome. Lanza's diagnosis of ASD was further reviewed by the State of Connecticut, Office of the Child Advocate, and found to be appropriate. Mellberg's diagnosis of autism was made by two independent evaluators, namely Dr. John Campbell and Captain Lisa Snow, MD. In regard to Breivik, Psychiatrists Professor Ulrik Fredrik Malt and Per Olav Naess both opined that he had Asperger's Disorder. In regards to autistic- based deficits, Lanza exhibited sensory sensitivities, deficits in communicating and in engaging in social relationships as well as a fixated, abnormal interest in violence and murder. On the other hand, Mellberg's symptoms of autism were not publically available and so no clinical presentation of his symptoms is possible. In regards to Breivik, there may have been a sensory component given that he took pictures of himself, engaged in role playing, very visual representations of himself, such as role playing and photographing himself in colorful uniforms to reinforce his fantasies of grandiosity. Also, his obsessive, overly elaborate detailed writings, which were both exceptionally lengthy and pedantic, may be symptoms of his ASD. "His social communication difficulties could make his fantasy life more appealing. The individual may then write and visually depict their ideal self and communicate their anger and need for superiority, through manifestos/writings/websites, and take on the role of a character; they also could communicate in scripts that they have learned thusly overcoming communication impairments that would normally hinder them in real life reciprocal communications. Thusly, taking on powerful characters with scripts and writing/visually depicting all of this replaces real life faceto-face social communications which would lead to failure and inferiority" [25]. 
In all three of the cases presented, mental health disorders also co-occurred alongside an ASD. For Adam Lanza, a sense of a threatening world was expressed in his Obsessive and Sensory Processing Disorders, as well as also experiencing a depression and homicidal/suicidal ideation. Mellberg was diagnosed with a Paranoid Personality Disorder and with Obsessive Compulsive/Anxiety features. Breivik was diagnosed with a Narcissistic Personality Disorder (NPD) (with antisocial traits) as well as experiencing a possible depression.

Although the symptoms that comprised their ASD, as well as their mental health disorders varied among the three mass shooters, the one predominant characteristic that they shared involved all three engaging in the steps along the Path to Intended Violence. Calhoun and Weston [26] proposed that "intended violence is a process of discreet, sequential, recognizable behaviors." Calhoun and Weston [27] called their practical model for threat assessment "the path to intended violence" and stated that hunters "move from feeling a grievance, to developing the idea that only violence can resolve the injury, to researching and planning the attack, to making preparations according to the dictates and the opportunities available, to breaching the target's security (however primitive or sophisticated that may be), and then to attack." The six behavioral steps or stages consist of the following: holding a grievance (e.g., a perceived sense of injustice, a threat or loss, a need for fame, or revenge), ideation (considering violence to be the only option, discussing one's thoughts with others, or modelling oneself after other assailants), research/planning (collecting information specific to one's target, or stalking the target), preparations (for instance, collating one's costume, weapon(s), equipment, transportation, or engaging in "final act" behaviors), breach (assessing levels of security, devising "sneaky or covert approach"), and attack (as summarized in [21]).

All three individuals had a personal grievance that served as the first step towards having a reason to engage in planned violence. For Lanza it was a sense of a threatening world, accompanied by a sense of significant loss in his life that comprised his significant grievances. For Mellberg, this sense of loss, injustice and need for retribution and revenge fueled his grievances, while for Breivik it was his sense of injustice, threat, loss, need for fame, and retribution that made up his grievances. Essentially, having significant grievances placed them all on the first step towards Intended Violence.

Since having grievances were common to all three mass shooter cases, their grievances were then expressed in their ideation. For instance, Lanza wrote stories and made drawings that depicted him killing others, being triumphant, and then killing himself. Mellberg uttered statements that he "enjoyed killing", and "that he could kill others in a school" during a psychiatric evaluation. Breivik shared his ideation in his 1,518 page Manifesto [28], and in distributing photos of himself as a high ranking Freemason in Knights Templar uniform, someone in weapons biological suit, and as a police officer with an assault rifle. Also, in his Manifesto part III, he urged that patriots for Europe should wage war against different groups (e.g., Muslims); he argued this because he believed that they were taking over Europe.

Also, common to all three shooter cases, they made the decision to use violence as a means of resolving their issues and grievances. Essentially it is at this point that they are solidly on the Path towards Intended Violence. According to Calhoun and Weston [26] "at some point it occurs to them that violence will correct the wrong, avenge the injustice. That is what distinguishes them: not the feeling of injustice, but the decision to use violence to avenge it." Subsequent to this step on the Path, all three individuals then engage in research and planning, preparing for the attack, breaching security and then attacking.

In regard to researching and preparing, Lanza remembers the school layout from when he was a student so no layout surveillance needs to be done; similarly, Mellberg knows the layout of the Air Force base, and in particular the Medical Treatment Center where his targets had their offices, namely a Psychiatrist and Psychologist who evaluated him and recommended discharge. Since Breivik planned to target the government buildings in Oslo, Norway, he asked taxi drivers and used his GPS to select best routes. The day before the bombings, he did a final reconnaissance of the area. Furthermore, both Lanza and Breivik prepared by playing shooter games and practiced gun shooting at a local range. There was no information regarding Mellberg's preparation with weapons (i.e., MAK 90) and having significant ammunition, except that he purchased them online; similarly, Lanza already had the car, driver's license and weapons in his home. Breivik purchased the guns, body armor, and diluted fertilizer, as well as researched the recipe for bomb making. All three individuals assembled their costume involving black pants and a shirt, and black boots; however, Breivik made his costume look like a policeman's uniform. Both Lanza and Breivik engaged in suspicious enquiries, where Lanza asked gun enthusiasts how to modify a semi-automatic to an automatic weapon, and Breivik asked taxi drivers how to efficiently travel from Oslo to Utøya Island. Also, all three engaged in final act behaviors; Lanza destroyed his computer CDs and killed his mother; Mellberg went out drinking and spent two to three thousand dollars in an adult entertainment establishment, while Breivik distributed his Manifesto and photos of himself to 6000 addresses on the internet.

In terms of breaching security, Mellberg was still able to access the Air base with his military identification card that he was allowed to keep. As a result, he was able to walk past security and walk right up and enter the Medical Treatment Center with two guns in a duffle bag. Lanza breached security by driving right up to the elementary school, parking right near the front entrance, leaving the car's doors open and weapons easily accessible in case of a firefight. Similarly, Breivik was able to drive right up to the government buildings in Oslo, park his van with the insignia removed, full of a prepared fertilizer bomb and then put out a sign indicating that water treatments were underway to account for the fertilizer smell. Subsequently, he got into his car and headed for Utøya Island.

In regards to attack, Lanza proceeded directly to the elementary school's entrance, shot out a large window and proceeded to 
engage in mass violence. Essentially, there was not an identified target for his violence, unlike Mellberg and Breivik. In Mellberg's case, although he shot at others, his primary targets included the Psychiatrist and Psychologist who last evaluated him and recommended discharge from the air force. In terms of Breivik, his primary target in Oslo was to kill the Prime Minister whom he held responsible for not doing enough to stem the takeover of Europe. In addition, he then targeted youth workers from a political party that had rejected him and whom he also held responsible for ruining and allowing Europe to be taken over.

\section{Discussion}

This paper sought to highlight some of the research identifying risk factors for mass violence in persons with an ASD. However, the vast majority of the individuals with an ASD do not engage in substantial violence or mass shootings. An analysis of three cases indicated that despite their motivations, triggers, stressors, and psychiatric disorders differing, all three cases uniformly engaged and proceeded along the Path towards Intended Violence. So essentially from a risk assessment and management perspective, it may be beneficial to analyze if any functional deficits from an ASD are directly linked to the mass violence, and how to identify and monitor individuals engaging in the Path towards Intended Violence. It appears to be that engaging in the Path towards Intended Violence is the critical pathway and common characteristics of some individuals with an ASD who have engaged in mass violence.

\section{Conclusion}

Although ASD-based deficits interacted or co-existed with psychopathology for all three of the case studies, it was when these two factors contributed to grievances, ideation (which included the violence-only decision/solution), research and planning, preparation, and breaching security, then substantial violence may occur. In conclusion, it appears to be that engaging in the Path towards Intended Violence is the critical pathway and common risk relevant characteristics of some individuals with an ASD who have engaged in mass violence.

\section{References}

1. Bowers TG, Holmes ES, Rhom A (2010) The nature of mass murder and autogenic massacre. J Police Cri Psych 25: 59-66.

2. Hart SD, Webster CD, Menzies RJ (1993) A note on portraying the accuracy of violence predictions. Law Human Behavior 17: 695-700.

3. Mulvey EP, Cauffman E (2001) The inherent limits of predicting school violence. Ame psy 56: 797-802.

4. Fox JA, Levin J (2003) Mass murder: An analysis of extreme violence. J App Psych Stu 5: 47-64.

5. Fox JA, DeLateur MJ (2014) Mass shootings in America: moving beyond Newtown. Homicide Studies 18: 125-45.

6. Im DS (2016) Template to perpetrate: an update on violence in autism spectrum disorder. Harv Rev Psychiatry 24: 14.

7. Sobsey D, Wells D, Lucardie R, Mansell S (1995) Violence and disability: An annotated bibliography. Baltimore, MD: Paul H. Brookes.

8. Woodbury-Smith MR, Clare IC, Holland AJ, Kearns A (2006) High functioning autistic spectrum disorders, offending and other law-breaking: findings from a community sample. J Forensic Psych Psychology 17: 108-20.

9. Mouridsen SE (2012) Current status of research on autism spectrum disorders and offending. Rese Autism Spectr Disorders 6: 79-86.

10. Mouridsen SE, Rich B, Isager T, Nedergaard NJ (2008) Pervasive developmental disorders and criminal behaviour. A case control study. Int J Offender Ther Comp Criminol 52: 196-205.

11. Tantam D (1991) Asperger's syndrome in adulthood. In U. Frith (Ed.), Autism and Asperger syndrome Cambridge: Cambridge University Press.

12. Murrie DC, Warren JI, Kristiansson M, Dietz PE (2002) Asperger's syndrome in forensic settings. Int J Forensic Mental Health 1: 59-70.

13. Peterson J, Skeem JL, Hart E, Vidal S, Keith F (2010) Analyzing offense patterns as a function of mental illness to test the criminalization hypothesis.

Psychiatric Services 61: 1217-22.

14. Peterson JK, Skeem J, Kennealy P, Bray B, Zvonkovic A (2014) How often and how consistently do symptoms directly precede criminal behavior among offenders with mental illness? Law and Human Behavior 38: 439.

15. Corner E, Gill P (2015) A false dichotomy? Mental illness and lone-actor terrorism. Law Hum Behav 39: 23.

16. Corner E, Gill P, Mason O (2016) Mental health disorders and the terrorist: A research note probing selection effects and disorder prevalence. Studies in Conflict \& Terrorism 39: 560-8.

17. Fitzgerald M (2010) Young violent and dangerous to know. Hauppauge, New York: Nova Science Publishers; 2010.

18. Fitzgerald M (2015) Autism and School Shootings-Overlap of Autism (Asperger's Syndrome) and General Psychopathy. Chapter 1. Retrieved on the 15th October 2016.

19. Allely CS, Wilson P, Minnis H, Thompson L, Yaksic E, et al. (2017) Violence is rare in autism: when it does occur, is it sometimes extreme? J psychology 151: 49-68.

20. Allely CS, Minnis H, Thompson L, Wilson P, Gillberg C (2014) Neurodevelopmental and psychosocial risk factors in serial killers and mass murderers. Aggression and violent behavior 19: 288-301.

21. Faccini L (2016) The application of the models of autism, psychopathology and deficient Eriksonian development and the path of intended violence to understand the Newtown shooting. Archives Forensic Psychol 1: 1-3.

22. Faccini L, and Allely CS (2016) Mass Violence in Individuals with Autism and Narcissistic Personality Disorder: A Case Analysis of Anders Breivik using the "Path to Intended and Terroristic Violence" Model. Aggression and Violent Behavior 31: 229-236.

23. Faccini L and Allely CS (2016) Mass Violence in an Individual with an Autism Spectrum Disorder: A Case Analysis of Dean Allen Mellberg using the "Path to Intended Violence" Model. Int J Psych Res. 
24. Faccini L and Allely CS (in press). Rare Instances of Individuals with Autism Supporting or Engaging in Terrorism. J Intellectual Disabilities and Offending Behaviour.

25. A. Al-Attar, (2016) personal communication.

26. Calhoun FS, Weston SW (2003) Contemporary Threat Management. San Diego, CA: Specialized Training Services.

27. Calhoun FS, Weston SW (2015) Perspectives on Threat Management. Journal of Threat Assessment and Management 2: 258-67.

28. Breivik A [Andrew Berwick] (2011) 2083: A European Declaration of Independence. 